\title{
DIREITO À EDUCAÇÃO E 500 ANOS DE REFORMA PROTESTANTE: AS CONTRIBUIÇÕES DE MARTINHO LUTERO
}

\author{
RIGHT TO EDUCATION AND 500 YEARS OF PROTESTANT \\ REFORMATION: THE CONTRIBUTIONS OF MARTIN LUTHER \\ DERECHO A LA EDUCACIÓN Y 500 AÑOS DE REFORMA
PROTESTANTE: LAS CONTRIBUCIONES DE MARTÍN LUTERO
}

Luciane Muniz Ribeiro Barbosa ${ }^{\mathrm{I}}$

Ana Elisa Spaolonzi Queiroz Assis ${ }^{\mathrm{I}}$

'Universidade Estadual de Campinas (UNICAMP), Campinas/SP - Brasil.

REsumo Este artigo busca ressaltar as contribuições de Martinho Lutero para a educação no movimento da Reforma Protestante, analisando-se os princípios que permaneceram, cinco séculos depois, no que se refere ao direito à educação. Foi realizada pesquisa bibliográfica, considerando-se os textos de autoria do próprio Lutero, bem como, de historiadores da educação e autores vinculados ao debate referente ao direito à educação. Para tanto, são levantadas questões relacionadas à concepção do direito à educação na atualidade, tanto aquelas consideradas internacionalmente quanto o seu histórico no Brasil, para, em seguida, resgatar as propostas de Lutero para a educação escolar no movimento da Reforma. Os resultados apresentam as propostas de Lutero defendendo uma educação escolar para todos, com caráter obrigatório e gratuito, e responsabilizando o Estado pela sua oferta, manutenção e supervisão, destacando que tais princípios permanecem presentes, 500 anos após a Reforma Protestante, sendo garantidos no ordenamento jurídico brasileiro, sem que necessariamente tenha se tornado realidade para todos.

Palavras-chave: Direito à educação; Martinho Lutero; Reforma Protestante.

Abstract The present article seeks to highlight the contributions of Martin Luther to education in the Protestant Reformation movement, analyzing the principles that remained, five centuries later, with regard to the right to education. Bibliographical research was carried out, considering texts written by Luther himself, as well, as by historians of education 
and authors related to the debate on the right to education. To this end, questions are raised regarding the conception of the right to education nowadays, not only those considered internationally, but also its history in Brazil, preparing the terrain to rescue Luther's proposals for school education in the Reformation movement. The results present the proposals of Luther defending a school education for all, with a gratuitous and obligatory character and recognizing the State responsible for its offer, maintenance and supervision, emphasizing that these principles remain present, 500 years after the Protestant Reformation, being guaranteed in the Brazilian legal order, without has necessarily become a reality for all.

Key-words: Right to education; Martin Luther; Protestant Reformation.

ReSumen El presente artículo busca resaltar las contribuciones de Martín Lutero para la educación en el movimiento de la Reforma Protestante, analizando los principios que permanecieron, cinco siglos después, en lo que se refiere al derecho a la educación. Se realizó una investigación bibliográfica, considerando los textos de autoría del propio Lutero, así como de historiadores de la educación y autores vinculados al debate sobre el derecho a la educación. Para eso, se plantean cuestiones relacionadas con la concepción del derecho a la educación en la actualidad, tanto aquellas consideradas internacionalmente como su histórico en Brasil, para luego rescatar las propuestas de Lutero para la educación escolar en el movimiento de la Reforma. Los resultados presentan las propuestas de Lutero defendiendo una educación escolar para todos, con carácter obligatorio y gratuito y responsabilizando al Estado por su oferta, mantenimiento y supervisión, destacando que tales principios permanecen presentes, 500 años después de la Reforma Protestante, siendo garantizados en el ordenamiento jurídico sin que necesariamente se haya hecho realidad para todos.

Palabras clave: Derecho a la educación; Martín Lutero; Reforma Protestante.

\section{INTRODUÇÃo}

O momento de passagem pelos 500 anos da Reforma Protestante, ocorrida no início do século XVI, é profícuo para analisar as consequências que tal movimento apresentou em diversas áreas, as quais não se restringiram aos países europeus, mas se expandiram afetando demais localidades e sociedades. É possível afirmar que as propostas de uma reforma inicialmente religiosa acabaram ultrapassando o âmbito da igreja em sua estrutura e questões eclesiásticas, atingindo não só a política, a educação e a economia, como as diversas questões que envolviam a sociedade da época (BARBOSA, 2017).

Martinho Lutero (1483-1546), um monge da ordem de Santo Agostinho, é quem inicia esse movimento de reforma da Igreja Católica após tornar-se doutor em Teologia. Entretanto, a Reforma Protestante não se restringiu à pessoa de Lutero e não foi desenvolvida por ideias e ações unicamente suas. Muitos homens compartilharam de tais ideais e o auxiliaram na luta em prol de uma reforma na igreja estendendo-a a outros reformadores em diferentes locais, como Calvino, na França, Zwinglio, na Suíça, John Knox, na Escócia, entre outros. 
Contudo, este trabalho propõe-se a analisar especificamente as ações de Martinho Lutero em prol da educação de sua época e as consequências de suas propostas para a concepção atual de direito à educação, que se fazem presentes ainda na atualidade, mesmo passados 500 anos da Reforma Protestante.

Compreendendo Lutero como o precursor e quem apresentou propostas concretas para uma reforma na educação escolar no movimento de reforma religiosa, avalia-se que sua atuação foi além da de um teólogo e erudito; revelou-se, por meio de seus escritos e suas defesas, um homem preocupado com as questões da igreja, da política e com o desenvolvimento de seu país e, por tais motivos, reivindicou mudanças basilares para a educação de todos (BARBOSA, 2011).

Se, por um lado, reconhece-se a extensa bibliografia sobre o campo do direito à educação, tanto no âmbito internacional como no nacional (ASSIS, 2012), por outro, a relação de Lutero com a educação tem revelado poucos estudos acadêmicos que ultrapassem o viés religioso. Dessa maneira, as considerações apresentadas neste trabalho são resultados de análise da bibliografia que envolveu os próprios textos de Martinho Lutero, bem como, historiadores da educação e autores vinculados ao debate a respeito do direito à educação.

Optou-se por exibir, inicialmente, as questões relacionadas à concepção do direito à educação na atualidade, bem como, os avanços e os desafios presentes historicamente na prescrição desse direito no Brasil; em seguida, serão resgatadas as propostas de Lutero para a educação escolar no movimento da Reforma Protestante e, posteriormente, se abordarão as análises suscitadas pelas ações de Lutero após cinco séculos de sua atuação no que se refere à educação.

\section{Direito À EdUCAÇÃo: UMA RELAÇÃo ENTRE OBRIGATORIEDAdE E GRATUIDADE?}

Ao analisar as orientações internacionais sobre o direito à educação, evidencia-se, atualmente, o prescrito no artigo 26 da Declaração Universal dos Direitos Humanos: ${ }^{1}$

1. Toda pessoa tem direito à educação. A educação será gratuita, pelo menos nos graus elementares e fundamentais. A educação elementar será obrigatória. (...)

2. A educação será orientada no sentido do pleno desenvolvimento da personalidade humana e do fortalecimento do respeito pelos direitos humanos e pelas liberdades fundamentais. A educação promoverá a compreensão, a tolerância e a amizade entre todas as nações e grupos raciais ou religiosos, e coadjuvará as atividades das Nações Unidas em prol da manutenção da paz.

3. Os pais têm prioridade de direito na escolha do gênero de educação que será ministrada a seus filhos (BRASIL, 1948).

Conteúdo semelhante sobre educação consta nos Pacto Internacional dos Direitos Civis e Políticos e Pacto Internacional dos Direitos Econômicos, Sociais e Culturais, ambos ratificados pelo Brasil, em 1992, que incorporaram os direitos constantes na Declaração Universal atribuindo a estes força jurídica obrigatória e vinculante (PIOVESAN, 2011). Esses três documentos compuseram a International Bill of Rights (Carta Internacional dos Direitos Humanos). 
Destacam-se, para a presente discussão, os princípios de gratuidade e compulsoriedade exigidos nos níveis elementares da educação, bem como, o papel da educação para o fortalecimento dos demais direitos humanos e liberdades fundamentais.

$\mathrm{Na}$ avaliação de Katarina Tomasevski (2001a), o século XXI inicia-se com um combate contra a incapacidade de alguns países de avançar da promessa para a efetivação da garantia da educação primária gratuita e obrigatória para todas as crianças. E, no que diz respeito à aliança entre essas duas características (gratuidade de compulsoriedade), a autora avalia que, tanto nos Tratados Internacionais de Direitos Humanos como nas leis dos diversos países que passaram a compreender que a educação compulsória requer obrigações por parte do Estado e da sociedade, nunca houve dúvidas sobre tornar a educação compulsória, sem torná-la gratuita (TOMASEVSKI, 2001a).

No que se refere à educação compulsória, Tomasevski (2001a) afirma que esta possui uma tradição muito mais longa que o próprio direito à educação, sendo que as lutas pela implementação da educação obrigatória, segundo Sacristán (2001), refletiram objetivos distintos ao longo da História:

A ideia foi defendida como meio de emancipação social e individual a partir da perspectiva ilustrada; foi uma forma de legitimar uma nova ordem social nascente; desempenhou o papel de mecanismo de integração social dos Estados nacionais modernos; transformou-se também em uma forma de vigilância simbólica disciplinadora dos indivíduos. Nas primeiras leis que a propuseram como ideal, falava-se de sua utilidade social e acreditou-se que fosse um dever moral; mais tarde, foi reconhecida como uma obrigação de estrito cumprimento e um direito das pessoas (SACRISTÁN, 2001, p. 15-6).

O reconhecimento da educação primária compulsória como parte dos Tratados Internacionais de Direitos Humanos e a mudança de visão sobre a criança como sujeito de direito, trazida pela Convenção Sobre os Direitos da Criança, passam a se refletir nas leis internas da maioria dos países no mundo (TOMASEVSKI, 2001a). Entretanto, a capacidade que os governos têm de implementar essas leis de educação compulsória e gratuita, bem como, as medidas para a sua aplicabilidade, variam (TOMASEVSKI, 2001a); para a autora (2001b), esse cumprimento requer um balanço entre direitos e deveres, liberdades e responsabilidades, orientadas pelas leis em geral e também pelas leis de direitos humanos, pois uma criança não pode ter o direito a uma educação gratuita a menos que o governo seja capaz de aumentar os recursos nela investidos, assim como a educação não pode ser obrigatória, sem que os pais aceitem que os seus filhos têm o direito à educação.

Sem a pretensão de se apresentar um histórico aprofundado sobre a compulsoriedade do ensino, ressaltam-se, neste debate, dois aspectos que desde as ações de Lutero em prol da educação escolar até os dias atuais têm se revelado uma conquista na luta pelo direito à educação de todos: um Estado responsável pela oferta (gratuita) e manutenção da educação escolar, que ofereça parte dessa educação em caráter obrigatório aos seus cidadãos, garantindo, assim, que todos tenham um mínimo de educação necessária para poder usufruir dos demais direitos constitutivos do estatuto da cidadania (OLIVEIRA, 2001). 
Assim, atualmente, pelo entendimento de que o direito à educação se mostra necessário para o usufruto dos demais direitos e para a participação do indivíduo na sociedade, a educação compulsória tem visto sua ampliação para além da educação primária, como prevista na legislação de diferentes países. Na avaliação de Tomasevski (2001a), essa tendência de alongamento da escolaridade obrigatória segue uma lógica dupla: por um lado, o aumento da idade de deixar a escola por meio da educação obrigatória prolongada impede as crianças de se aventurarem na idade adulta muito cedo, o que se revela particularmente importante na luta contra o trabalho infantil ou casamento precoce; por outro lado, a educação obrigatória prolongada fornece a todas as crianças certa "escolaridade de núcleo comum", cada vez mais exigida pela mudança em direção a sociedades e economias ancoradas no conhecimento, reforçadas pela interação entre a globalização e educação local; ainda em um modelo ideal de educação inclusiva, todas as crianças podem se socializar na mesma escola e sala de aula, independentemente do seu sexo, raça, proveniência, religião, condição econômica ou deficiência. Dessa maneira, todas as crianças devem frequentar a escola, porque a educação é definida como um bem público (TOMASEVSKI, 2001b).

Sacristán (2001), apesar de reconhecer a escolarização como um caminho problemático para o alcance de maior igualdade entre as pessoas, avalia que sua inexistência, suas deficiências ou as diferenças na quantidade de escolaridade recebidas certamente conduzem a uma desigualdade ainda maior, não somente no campo da educação, mas, por conseguinte, para o desempenho do exercício de muitas outras oportunidades e atividades.

No que se refere ao contexto brasileiro, em uma análise histórica depreende-se que temas como a compulsoriedade e a gratuidade da educação escolar sempre se fizeram presentes nos debates constituintes, entretanto, com muitos descompassos (ASSIS, 2012).

A primeira "Constituição Política do Império do Brazil", de 1824, no tocante à educação, indica somente dois incisos no artigo 179, sendo um deles determinando a gratuidade da instrução primária para todos os cidadãos. Apesar da expressão de "gratuidade", o texto constitucional não abrangeu toda a população, restringindo apenas aos considerados cidadãos na época e não gerando qualquer garantia social de efetivação desse direito. ${ }^{2}$ Posteriormente, com a reforma proposta pelo Ato Adicional de 1834, foi cedida às Assembleias Provinciais a competência de legislar e promover a instrução pública em estabelecimentos próprios. Dessa forma, coube às províncias a tarefa de administração do ensino primário e secundário (ZICHIA, 2008). É somente após 1845 que o governo central começa a se preocupar com a instrução primária, sendo possível encontrar nos relatórios ministeriais a discussão acerca da necessidade de o ensino ser obrigatório. No entanto, tal proposta era

\footnotetext{
2 De acordo com Assis (2012), eram considerados cidadãos nesse período "os nascidos no Brasil, ainda que de pais estrangeiros e que não estivessem a serviço de sua nação, quer fossem libertos ou ingênuos (art. $6^{\circ}$., I CF/1824); os filhos de pai brasileiro e ilegítimos de mãe brasileira, nascidos em país estrangeiro, que viessem estabelecer domicílio (art. $6^{\circ}$., II CF/1824); e os filhos de pai brasileiro que estivesse em país estrangeiro a serviço do Império sem que viessem estabelecer domicílio (art. $6^{\circ}$., III CF/1824); todos os nascidos em Portugal que, à época da proclamação da Independência das Províncias, aqui aderiram expressa ou tacitamente pela continuação de sua residência (art. $6^{\circ}$., IV CF/1824); e os estrangeiros naturalizados (art. $6^{\circ}$., V $\mathrm{CF} / 1824)$. Mesmo reconhecendo libertos e ingênuos como cidadãos, fato é que, de acordo com as castas, o exercício de cidadania restringia-se àqueles com poder aquisitivo" (p. 54).
} 
considerada inexequível para os presidentes das províncias, pois ainda que em algumas passassem a existir leis determinando a obrigatoriedade, estas não se faziam eficazes (ZICHIA, 2008).

Após a proclamação da República e com a criação de um Estado laico mediante a separação Estado-Igreja, esperava-se que a constituição seguinte explicitasse os princípios do direito à educação de todos, destacando aqueles como a gratuidade e a obrigatoriedade. No entanto, "a hegemonia de uma visão individualista do liberalismo determinou a derrota das poucas emendas que propuseram o ensino obrigatório na constituinte Republicana de 1891" (OLIVEIRA, 2001, p. 17). Embora não tenha sido explicitada no texto constitucional, a ideia de se garantir a gratuidade e a obrigatoriedade do ensino primário tornou-se hegemônica ao longo da República Velha (OLIVEIRA, 2001).

Será a Constituição da República dos Estados Unidos do Brasil, de julho de 1934, que, acomodando interesses da Igreja Católica e propostas dos Pioneiros da Escola Nova, dedicará pela primeira vez um capítulo à educação e também a proclamará como um direito de todos, devendo ser ministrada "pela família e pelos poderes públicos, cumprindo a estes proporcioná-la a brasileiros e estrangeiros domiciliados no País, de modo que possibilite eficientes fatores da vida moral e econômica da nação, e desenvolva num espírito brasileiro a consciência de solidariedade humana" (art. 149, CREUB/34).

Segundo Assis (2012), a Constituição de 34 dará início ao vínculo existente entre obrigatoriedade e gratuidade no direito à educação no Brasil, estabelecendo-se no que hoje chamamos de primeira fase do ensino fundamental e mantendo-se até os dias atuais. Além disso, há outros dois aspectos importantes: o fato de ser um "ensino primário integral" (parágrafo único, art. 150, CREUB/34) e extensivo aos adultos, de forma que a educação para todos acaba ganhando contornos mais específicos e plurais relativos a essa totalidade; e em segundo lugar, aquilo que tange aos demais níveis de ensino, há apenas a tendência à gratuidade da segunda fase do ensino fundamental, do ensino médio e da educação superior, sem mencionar a obrigatoriedade.

A Constituição dos Estados Unidos do Brasil, decretada por Getúlio Vargas em novembro de 1937 e decorrente do golpe militar no mesmo ano, priorizou o papel da família sobre a educação, apresentando ao Estado a possibilidade de ser apenas um colaborador subsidiário nessa oferta:

Nota-se o Estado ausente quanto à sua obrigação no oferecimento da educação
(art. 128/CF, 1937), pois ao pontuar que é dever do Estado contribuir, dentre
outras coisas, com o ensino, significa dizer "ter parte numa despesa", "con-
correr para a realização de um fim", "cooperar" (HOUAISS, 2001); diferente-
mente do dever de oferecer, que quer dizer "dar, como oferta", "proporcionar",
"prestar-se" (HOUAISS, 2001). A escolha do verbo que acompanha a situação
de obrigação estatal está em congruência com uma ação subsidiária do Estado
acerca do direito à educação. O artigo 129 reforça a atuação supletiva do Estado
junto à rede particular, pois é ela que vem primeiro para suprir as necessidades
educacionais, o Estado entra em segundo plano naquilo que ela for insuficiente.
É tão ilusória a ideia do sistema público gratuito que, mesmo quando o ensino 
fosse oferecido pelo Estado, haveria a possibilidade de se cobrar por ele caso não fosse comprovada a "escassez de recurso" por parte do alunado (art. 130, CF/1937) (ASSIS, 2012, p. 56).

Além disso, apesar de o ensino primário ser declarado como obrigatório e gratuito, o texto constitucional não excluía "o dever de solidariedade dos menos para com os mais necessitados; assim, por ocasião da matrícula, será exigida aos que não alegarem, ou notoriamente não puderem alegar escassez de recursos, uma contribuição módica e mensal para a caixa escolar" (art. 130, CEUB/37).

Além da gratuidade flexibilizada, o texto constitucional de 1937 revela que o ideário presente é o de um ensino primário obrigatório a todos, mas a ser definido pela família, visto que a educação passa a ser entendida como, com base nesses dispositivos, um dever e direito natural dos pais e não das crianças, formulação em termos muito semelhantes às concepções católicas sobre o tema (OLIVEIRA, 2001). Para Assis (2012), trata-se de um "dever camuflado de direito" (p. 56), pois:

[...] o dever de educar da família é que permite a existência do direito à educação, e a efetivação deste direito depende de certas condições, dentre elas, financeiras. Então, da mesma forma que o dever de educar da família aparece com mais força na Constituição de 1937, a relação 'poder aquisitivo x possibilidade de educar', também. “Aos pais miseráveis assiste o direito de invocar o auxílio e proteção do Estado para a subsistência e educação da sua prole" (art. 127, $\mathrm{CF} / 1937$ ). Ora, se a educação fosse de fato um direito, não criaria o direito de requerer este direito. Fica nítida a transformação do direito num dever, restrito aos que podem fazê-lo (ASSIS, 2012, p. 57).

Nesse sentido, ainda que a expressão "todos" continuasse a fazer parte do texto constitucional, sem as restrições de uma compreensão restrita de cidadão, identificar a família como responsável primeiro da educação e vincular a aspectos econômicos, acaba dando novos contornos a ela, de forma que a totalidade fosse algo bastante relativo.

Após a superação do Estado Novo, a Constituição dos Estados Unidos do Brasil, de setembro de 1946, apresenta uma formulação semelhante à de 1934, no que se refere à responsabilidade pela educação, bem como, ao escopo daqueles que devem ser sujeitos de direito, dando continuidade à ideia de obrigatoriedade do ensino presente no texto de 1937: Artigo 168 - A legislação do ensino adotará os seguintes princípios: I - o ensino primário é obrigatório e só será dado na língua oficial. Nesse contexto, obrigatoriedade e gratuidade continuam juntas apenas no que tange à primeira fase do ensino fundamental, de forma que nas demais (segunda fase do ensino fundamental, ensino médio e educação superior) a falta de recursos poderia levar a uma possível gratuidade, já que "o ensino oficial ulterior ao primário sê-lo-á (gratuito) para quantos provarem falta ou insuficiência de recursos" (art. 168, II CEUB/46) (ASSIS, 2012).

Anos mais tarde, iniciada a ditadura, com o Golpe Militar de 1964, surge a necessidade de um novo ordenamento jurídico, que resultou na Constituição da República Federativa 
do Brasil, de janeiro de 1967. Nesse texto, a responsabilidade pela educação continua explicitada da mesma forma que nas constituintes anteriores. Todavia, amplia-se o período de escolarização obrigatória e gratuita para oito anos, envolvendo todo o ensino fundamental nos estabelecimentos oficiais (Art. 168, CRFB/67).

A Emenda Constitucional $\mathrm{n}^{\circ}$. 1, de 1969, que ficou conhecida como "Constituição de 1969", formalizou pela primeira vez em nível constitucional a educação como "direito de todos e dever do Estado". Até esse momento, uma análise das constituintes revela que, no que diz respeito à definição das instituições responsáveis pela educação, o Brasil sofreu uma forte influência das concepções católicas, resultando na precedência da família sobre o Estado, na escolha da educação. Tal primazia revelou-se, ao longo da História, na opção dos pais pela matrícula de seus filhos em escolas privadas ou pelo ensino em casa.

Assis (2012) ressalta dois aspectos nesse texto constitucional de 67, alterado em 69. O primeiro deles é evidenciar que há um retorno do protagonismo das instituições particulares, ocorrido na Constituição de 1937, uma vez que teriam amparo técnico e financeiro do sistema público, incluindo bolsas de estudo (art. 168, § 2º, CRFB/67). O segundo, é destacar que o texto inaugura a ampliação da obrigatoriedade e gratuidade para a segunda fase do ensino fundamental, até então restrita à primeira fase, de forma que o ensino médio e o ensino superior poderiam contar com a gratuidade no caso da comprovação de falta de recursos e bom aproveitamento escolar (art. 168, § $3^{\circ}$., III CRFB/67).

Importante destacar que a ampliação da gratuidade e obrigatoriedade advinda do texto de 69 não pode ser entendida como manutenção de uma educação para todos no sentido republicano prevalecentes nos textos de 34 e 46 , pois, se nesses textos o conjunto normativo visava uma formação cidadã livre, no caso de 69 trata-se de uma formação cidadã para a obediência e proliferação do regime, usufruindo da totalidade em favor da manutenção de um projeto de Estado opressor e não emancipador. Em outras palavras, o direito à educação para todos acaba sendo usado em prol de objetivos bastantes distintos a depender do caráter governante e dos projetos societários postos em marcha.

A Constituição Federal de 1988 representa um grande marco para a educação no Brasil, pelas inovações e conquistas no que tange à garantia do direito à educação de todos. No texto da Carta Magna, a educação insere-se no Título II que trata dos Direitos e Garantias Fundamentais, sendo apresentada no Capítulo II ("Dos Direitos Sociais") como um direito social (art. $6^{\circ}$.). Entretanto, é no Capítulo III ("Da Educação, da Cultura e do Desporto") que a educação encontra uma Seção (I) própria (artigos 205 ao artigo 214) para regulamentar o tema. No total, a CF/88 e o Ato das Disposições Constitucionais Transitórias (ADCT) "apresentam cinqüenta e cinco artigos que tratam direta ou indiretamente sobre o direito à educação" (MORETTI, 2013, p. 44), especificando a abrangência desse direito, seus objetivos e princípios, forma de organização do ensino, entre outros; Ranieri (2009) avalia que "a educação é o direito social que mereceu o maior número de dispositivos no atual texto constitucional" (p. 316).

O artigo 205, primeiro do capítulo sobre a educação, não somente estabelece os objetivos da educação, como também afirma a precedência do Estado pelo dever de educar 
(OLIVEIRA, 2001, p. 24). Os princípios da gratuidade e obrigatoriedade sofreram ampliação após a Emenda Constitucional n n . 59/2009, vigorando atualmente o seguinte texto para o artigo 208, sobre o dever do Estado para com a educação que deve ser efetivado mediante a garantia de: "I - educação básica obrigatória e gratuita dos 4 (quatro) aos 17 (dezessete) anos de idade, assegurada inclusive sua oferta gratuita para todos os que a ela não tiveram acesso na idade própria".

Entende-se como das maiores conquistas brasileiras no campo da educação o fato de a $\mathrm{CF} / 88$ declarar o acesso ao ensino obrigatório e gratuito como um direito público subjetivo (art. 208, $\S 1^{\circ}$.), introduzindo mecanismos de se exigir do Poder Público o cumprimento de tal direito e responsabilizando-o tanto pela oferta irregular (art. 208, $\S 2^{\circ}$.) quanto pela tarefa de recensear os educandos, fazer-lhes a chamada e zelar, junto aos pais ou responsáveis, pela frequência à escola (art. 208, $\S 3^{\circ}$.). Nesse sentido, frente aos demais textos constitucionais, há uma preocupação em garantir que a expressão "para todos" seja compreendida de maneira ampla e sem restrições, dando ênfase, não só com a Constituição, mas em especial com as legislações infraconstitucionais, às minorias e camadas populares desfavorecidas.

$\mathrm{O}$ fato de, atualmente, no ordenamento jurídico vigente, obrigatoriedade e gratuidade se referirem à idade do sujeito de direito, no caso, de 4 a 17 anos, não contemplando fases específicas da Educação Básica, será analisado por Assis (2017) como uma perda. Nas palavras da autora:

\footnotetext{
O recorte etário da Educação Básica causa efeitos bastante distintos de um recorte por etapas de ensino - Educação Infantil, Ensino Fundamental e Ensino Médio (art. $4^{\circ}$., III, LDBEN) -, vez que na primeira opção, acompanha a necessidade escolar específica do indivíduo sem garantir que siga um percurso formativo livre de evasões; e na segunda, a garantia tem margem de restrição muito maior, porque vinculada a um percurso formativo diretamente relacionado o que temos chamado de "idade própria" (ASSIS, 2017, p. 46).
}

De acordo com a autora (ASSIS, 2012; 2017), para que seja um dever cobrado de imediato ao Estado, vale dizer, um direito público subjetivo, é preciso que reúna as características de obrigatoriedade e gratuidade, de forma que todo indivíduo fora da faixa etária determinada, ainda que tenha assegurada a gratuidade, perde um dos patamares de demanda do direito social, pois sai do âmbito da discussão coletiva recaindo no âmbito da demanda individualizada e perdendo força quando se discute a efetivação da política pública. Tal temática, frente aos desdobramentos atuais das relações entre cumprimento do Plano Nacional de Educação e restrições orçamentárias, terá novos desdobramentos que carecerão de acompanhamento para que não ocorra a redução de direitos sociais, em especial, o direito à educação.

Neste contexto, avalia-se que tanto no âmbito internacional como no nacional, o direito à educação sofreu alterações ao longo da História, mantendo em sua concepção princípios como os da obrigatoriedade e gratuidade vinculados ao dever de ação do Estado na garantia desse direito. 


\section{Martinho Lutero e o direito À educaÇão no movimento da Reforma Protestante}

Tanto a atuação de Lutero no movimento da Reforma Protestante, como suas propostas de mudança na educação da época, devem ser compreendidas no contexto histórico e cultural da Alemanha do século XVI, tendo clareza de que, nesse período, a Educação apresentava-se como atividade exclusiva da igreja com objetivos e público-alvo bem definidos (Cf. BARBOSA, 2017).

As propostas de Martinho Lutero para a Educação encontram-se principalmente em dois textos de sua autoria: "Aos Conselhos de todas as cidades da Alemanha para que criem e mantenham escolas cristãs", de 1524 e "Uma Prédica para que se mandem os filhos à Escola", de 1530.

O primeiro, de 1524, trata-se de uma carta que foi escrita por Lutero visando atingir os dirigentes e câmaras municipais das cidades da Alemanha. Foi publicada e reeditada em várias cidades do país e traduzida para o latim no mesmo ano, bem como, para o inglês, espanhol e outras línguas modernas ainda no século XVI. Nestor Beck (1995) avalia que esse texto em alemão se encontra nas principais edições das obras de Lutero e que ele foi o responsável por abrir "caminho para a disseminação do ginásio humanista cristão em toda a Europa" (LUTERO, 1995, p. 302).

De acordo com Ricardo Rieth (2000), Lutero teria notado que, com a propagação da Reforma, diversos mosteiros e conventos teriam se esvaziado, o que apesar de representar um ganho para a pregação evangélica, significou uma destruição dos recursos materiais e humanos que sustentavam muitas escolas.

Dessa forma, insatisfeito com essa situação, Lutero teria apelado às autoridades das cidades alemãs para intervir em prol de uma educação escolar que ele expõe, no texto de 1524, como deveria ser. Nota-se que ele teve repercussões na sociedade da época, pois, na introdução do sermão por ele escrito em 1530, Lutero afirma ter recebido notícias de que em muitas cidades onde os conselhos não se preocupavam com escolas "houve muitos cidadãos íntegros que com insistência diária obrigaram o conselho a instalar escolas e paróquias" (LUTERO, 1995, p. 329).

Já o texto "Uma Prédica para que se mandem os filhos à Escola", foi escrito por Lutero em julho de 1530 e publicado em Wittemberg, em agosto do mesmo ano. Nesse período, Lutero encontrava-se refugiado na fortaleza de Coburgo e, de acordo com Nestor Beck (1995), na introdução desse texto, esse foi o momento em que ele aproveitou para realizar projetos literários e assessorar, por cartas, o eleitor da Saxônia durante a assembleia imperial em Augsburgo.

O texto foi dedicado por Lutero ao secretário do Conselho da cidade de Nürnberg, Lázaro Spengler, que havia instituído e instalado, nessa cidade, em 1526, por iniciativa e orientação de Filipe Melanchthon, o Ginásio de Egídio, que segundo o próprio Lutero, era uma excelente e maravilhosa escola com professores dos mais qualificados (LUTERO, 1995). 
Lutero explicita seu objetivo e o público para quem teria escrito a exortação:

[...] para os pregadores de toda parte, para que conclamem as pessoas a enviarem seus filhos à escola. (...) É meu desejo que traga bons resultados. Dediquei-o a V. S $\mathrm{S}^{\mathrm{a}}$ com a única intenção de lhe dar tanto mais autoridade para que, se ele o merece, seja lido também entre vós por vossos cidadãos (1995, p. 327).

Ou seja, a obra destinava-se aos pregadores e autoridades seculares para que pregassem e divulgassem o seu conteúdo a toda a população exortando os pais quanto aos benefícios e prejuízos para a igreja e para o Estado em se promover ou negligenciar a educação escolar cristã que ele havia anunciado já no texto de 1524 .

Segundo Rieth (2000), após o escrito de 1524, que apresentou repercussões positivas, as condições para a educação escolar estavam sendo dadas, mas "os pais ainda não tinham plena consciência da importância e da necessidade de enviar seus filhos às escolas" (p. 5). Além da falta de compreensão, apontada por esse autor, Lutero invoca outro motivo, suscitado pelo desenvolvimento econômico, pelo qual os pais estavam deixando de enviar os filhos à escola e contra o qual ele rebate asperamente:

[...] há muito motivos para desviar as crianças da escola e servirem ao dinheiro (a saber, o comércio). (...) não há o que temer a não ser que algum idólatra ou escravo de ídolos (refiro-me ao dinheiro) tire seu filho da escola alegando: 'Se meu filho sabe calcular e ler é o que basta' (...) (LUTERO, 1995, p. 327-8).

Apesar desses dois textos serem os que explicitam as propostas de Lutero para uma reforma no sistema escolar, cabe ressaltar aspectos relevantes apresentados por BARBOSA (2007): as questões de caráter conceitual, bem como, os princípios presentes nessa proposta, que evidenciam sua preocupação com a doutrina dos dois reinos (por ele explicitada em outros textos), compreendendo-se "o quão relevante seria tanto para o Estado (a "mão esquerda de Deus") como para a igreja (sua "mão direita"), pais compromissados e cidadãos bem-educados para atuarem no governo secular e espiritual" (p. 166). Lutero não tinha como objetivo desenvolver uma teoria cristã de educação, mas "sim, seguir estimulando a sociedade a empenhar-se por uma educação formal de qualidade" (RIETH, 2000, p. 5), dada a compreensão que ele tinha da atuação de Deus no mundo por meio dos dois governos (BARBOSA, 2007).

Antes de resgatar as propostas de Lutero para a educação e sua influência para a concepção do direto à educação na atualidade, cabe ressaltar que seus intentos na área da educação não foram idealizados e realizados sozinhos. Nesse processo destacam-se principalmente Filipe Melanchthon (1497-1560) e Johannes Bugenhagen (1485-1558). Melanchthon, humanista alemão, foi amigo pessoal de Lutero até a sua morte e forte influenciador de suas propostas sendo, em alguns momentos, difícil reconhecer a autoria e originalidade de determinadas ideias. Considerado o ministro da educação de Lutero (NUNES, 1980), tornou-se professor da universidade de Wittemberg aos 21 anos de idade, e ficou conhecido como o "preceptor da Germânia", diante de sua capacidade de promoção e organização das 
escolas, que tentava efetuar uma convergência entre humanismo e luteranismo (CAMBI, 1999, p. 250), atuando na escrita de manuais, organização de sistemas escolares e supervisão de escolas.

Já Bugenhagen, após ter aderido ao luteranismo em 1520, chegou a ser considerado o "pai da Escola primária pública alemã" (LUZURIAGA, 1959, p. 8) dada a sua atuação para que em diversos estatutos de diferentes cidades do norte da Alemanha constassem preceitos sobre a educação pública, ordenando-se a criação de escolas, no processo de reorganização de igrejas. Na avaliação de Nunes (1980), as realizações de Bugenhagen em prol das escolas protestantes germânicas chegaram a superar as de Lutero e Melanchthon.

Assim, com influência e colaboração de amigos, Lutero apresenta propostas de reforma na educação escolar em meio ao movimento da Reforma na igreja. Tais propostas podem ser organizadas em dois grandes eixos referentes à Organização do Sistema Escolar e aos Princípios e Fundamentos que deveriam nortear essa educação.

Os principais aspectos contemplados nas propostas de Lutero para a organização de um sistema escolar versam sobre temas relacionados ao currículo, métodos, professores e forma de financiamento das escolas (Cf. BARBOSA, 2007). Nesta análise, se dará destaque ao segundo eixo, buscando evidenciar os princípios nele presentes que permanecem na concepção atual do direito à educação.

O primeiro princípio a ser considerado é de uma educação para todos, com objetivos previstos. Ainda que historiadores da educação apresentem posições distintas sobre a origem da educação popular (como a experiência dos Irmãos da Vida Comum ou as cidades italianas no final da Idade Média [NUNES, 1980]), destacam-se as propostas e ações de Lutero em prol de uma educação que não fosse mais destinada exclusivamente à determinada classe social e com fins de formação para a vida eclesiástica. Assim, ele reivindica que todos, os "filhos dos patrões" e os "filhos de gente pobre", frequentem a escola (LUTERO, 1995, p. 342).

Em seu discurso, faz um apelo para que as famílias com piores condições financeiras não instruíssem os filhos apenas para exercerem um ofício e contribuírem com o rendimento familiar, mas especialmente essas crianças deveriam ser enviadas à escola para aprender a ler, escrever, entender o latim, entre outros, e futuramente exercerem profissões comuns na sociedade.

Ao falar sobre a necessidade de também enviar os "filhos dos patrões" para as mesmas escolas, Lutero evidencia utilidades diferentes dessa educação escolar dependendo da condição econômica e social das famílias. Por isso, reitera que as famílias mais abastadas não deveriam ter como objetivo somente a formação de seus filhos para o ministério eclesiástico, mas também para exercerem cargos de autoridade secular (como um príncipe, senhor ou conselheiro dos municípios): "para aprender a pregar, governar e administrar a justiça, tanto no estado clerical ou secular, não bastam sequer todas as ciências e línguas do mundo [...]" (LUTERO, 1995, p. 328).

Não é explícito nos escritos de Lutero a proposta de escolas distintas para os diferentes grupos de crianças, ressaltando apenas diversos objetivos e utilidades da educação es- 
colar (ainda que historiadores apresentem, nas décadas seguintes, a organização de escolas distintas dependendo do público que recebia (LUZURIAGA, 1963).

Essa utilidade social que Lutero apresenta como objetivo da instrução também é diferenciada dependendo do gênero (MANACORDA, 1989). Assim, respeitando uma divisão social do trabalho da época, ele conclama que meninos e meninas fossem educados para cumprirem seus deveres sociais: os meninos deveriam tornar-se homens educados que governariam o Estado, igreja, países; enquanto as meninas deveriam ser educadas para o governo da casa, dos filhos e da criadagem.

Tal proposta de Lutero destaca-se diante do papel que as mulheres exerciam no século XVI e as oportunidades mínimas ou inexistentes de acesso a bens culturais que cabiam a quase todas elas, variando pouco segundo a classe à qual pertenciam. Apesar da constatação da existência de uma educação para meninas anterior à proposta de Lutero, este se diferenciou pela defesa de uma educação elementar para as garotas, que até então não tinham tradição de escolarização. Frederick Eby (1976) confirma o avanço dado por Lutero e seus companheiros nesse sentido, afirmando que "embora a Reforma não tenha originado a educação para meninas, deu ao movimento um impulso vigoroso e renovado", sendo que, em 1528, Bugenhagen, em seu regulamento de Brunswick, estabeleceu escolas para meninas em cada bairro da cidade (EBY,1976, p. 118).

De acordo com Andrea Schulte (2002), mesmo destinando a educação das mulheres para o serviço doméstico (não avançando muito no que ocorria em sua época) e não almejando o prosseguimento dos estudos para elas, pode-se afirmar que houve uma contribuição para que as mulheres tivessem acesso a habilidades elementares em leitura, escrita e aritmética, passos significativos para a construção da emancipação da mulher.

Dessa maneira, apesar de apresentar objetivos diferentes da educação escolar dependendo da origem, condição e gênero das crianças, ressalta-se o aspecto fundamental em tal proposta de Lutero: ele amplia o público-alvo que deveria receber educação escolar, estendendo-a para todos: ricos e pobres, meninos e meninas. Ainda que tenha havido experiências anteriores de oferta de educação elementar popular, Manacorda (1989) e Nunes (1998) ressaltam os progressos nessa área resultantes da força política e impulso prático de Lutero, bem como, o interesse social pela educação popular, nítido nas regiões afetadas pela Reforma Protestante.

Um segundo princípio presente nas propostas de Lutero para a educação é o seu caráter público estatal. Ele defendeu que a educação deixasse de ser monopólio e responsabilidade da igreja, transferindo-a para o Estado, na instância das autoridades municipais.

Compreendendo que, para Lutero, o Estado possuía um caráter cristão e assumia o papel de governar como a mão esquerda de Deus, este, diante da igreja em decadência, deveria se responsabilizar pela educação da população e promover escolas cristãs para que crianças e jovens fossem instruídos e pudessem atuar tanto na esfera espiritual como na secular (BARBOSA, 2011).

Franco Cambi (1999) também compreende como consequência do objetivo da Reforma, ao propor como fundamento um contato mais estreito e pessoal entre crente e Escrituras: [...] a posse elementar da cultura (em particular a capacidade de leitura) e, de 
maneira mais geral, para as comunidades religiosas, a necessidade de difundir essa posse em nível popular, por meio de instituições escolares públicas mantidas a expensas dos municipios (CAMBI, 1999, p. 248, grifos do autor).

Com essa visão, Lutero reivindica, não aos príncipes (que poderiam ou não aderir ao movimento da reforma religiosa), mas às autoridades das cidades, que se tornassem responsáveis pela criação, manutenção, financiamento das escolas e supervisão ${ }^{3}$ destas. Teriam também a tarefa de supervisionar os pais para que estes realmente enviassem os filhos à escola.

\begin{abstract}
Por isso certamente caberá ao conselho e às autoridades dedicarem o maior esforço à juventude. Sendo curadores, foram confiados a eles os bens, a honra, o corpo e a vida de toda a cidade. [...] o melhor e mais rico progresso de uma cidade é quando ela tem cidadãos sensatos honestos e bem educados (LUTERO, 1995, p. 309).
\end{abstract}

Nesse ponto, diante do contexto histórico da época e o decorrente da Reforma Protestante, destaca-se o caráter estatal da educação a ser oferecida para todos. Para além de uma transferência da igreja para o Estado diante da tarefa da educação escolar, enfatiza-se a ideia do dever do Estado em construir e financiar escolas para todos.

Alguns historiadores atribuem a Lutero a criação de escolas públicas no sentido de serem criadas, organizadas e financiadas pelas autoridades oficiais (LUZURIAGA, 1959; LOPES, 1981). Para Hilsdorf (2006), a historiografia da educação apresenta experiências de escolas elementares populares e públicas, anteriores a Lutero, contudo, Luzuriaga (1959) destaca a atuação do reformador pela maneira insistente que chama a atenção das autoridades públicas para a criação e manutenção de escolas. Já Defreyn (2004) apresenta como consequência da Reforma Protestante o fato de que a educação "foi legitimada e institucionalizada como uma tarefa pública, deixando de ser uma questão particular ou de interesse apenas da igreja como instituição" (p. 102).

Desse dever do Estado para com a oferta da educação escolar para todos, depreende-se também o princípio da gratuidade presente na proposta de Lutero (CAMBI, 1999). Em seus textos, exibe claramente a proposta de que as autoridades oficiais utilizem recursos próprios (ou confiscados dos bens eclesiásticos, como decorrência da reforma religiosa (DEFREYN, 2004) para que as escolas sejam criadas e mantidas. Ainda que apresente aos pais a possibilidade de contribuir com doações para o sustento da escola, considera responsabilidade dos conselhos municipais das diversas cidades da Alemanha a tarefa pelo financiamento da educação. Tal dever do Estado mostra como consequência a gratuidade da educação escolar que ele propõe que seja, inclusive para os pobres.

\footnotetext{
3 De acordo com Eby (1976), a atividade de visitação e supervisão das escolas é um dos aspectos da educação moderna que teve sua origem na Reforma Protestante. Melanchthon, com o auxílio de Lutero e Bugenhagem, escreveu o texto "Instrução dos visitadores aos párocos", um roteiro para supervisão das escolas da época.
} 
Outro princípio que merece destaque nas propostas de Lutero para a educação de sua época é o da obrigatoriedade de frequência à escola. Ele não se ampara no sucesso ou não de seu apelo às famílias, mas reivindica uma educação obrigatória, destacando o papel do Estado na supervisão do cumprimento de tal obrigatoriedade: além da criação, manutenção e supervisão das escolas "[...] também as autoridades têm o dever de obrigar os súditos a mandarem seus filhos à escola" (LUTERO, 1995, p. 362).

Para Eby (1976):

Lutero deve ser reconhecido como o primeiro reformador moderno a defender a educação obrigatória. [...] Insistiu em que era obrigação das autoridades municipais e dos príncipes estabelecer e sustentar escolas; e foi tão longe a ponto de exigir, para o bem do Estado, da cidade e da Igreja, que os pais fossem obrigados a enviar seus filhos à escola (p. 62).

Dessa maneira, ressalta-se que o princípio da obrigatoriedade presente nas propostas educacionais de Lutero atribui aos pais o dever de enviar os filhos à escola; às crianças, a obrigatoriedade de frequência; e às autoridades, a garantia de oferta e supervisão quanto ao atendimento. Uma situação bastante clara nos dias atuais, em especial considerando o ordenamento jurídico brasileiro e que, inclusive, tem repercussões na forma de reclamar o direito frente ao Poder Judiciário.

Historiadores da educação como Luzuriaga (1959) e Cambi (1999) reconhecem a obrigatoriedade da educação como uma das principais características da educação pública cristã decorrente da Reforma Protestante. Barbosa (2007) afirma que, se antes de Lutero houve registros de oferta de uma educação popular elementar, este teria sido um dos pioneiros em acrescentar a ela o princípio de obrigatoriedade do ensino.

Assim, mesmo no contexto do século XVI, em que a igreja detinha, por séculos, a oferta da educação para poucos, com formação exclusiva para o sacerdócio, ressaltam-se as propostas de Lutero defendendo a educação escolar para todos, com caráter obrigatório e tendo o Estado como o responsável pela sua oferta, manutenção e supervisão.

\section{CONSIDERAÇÕES FINAIS}

Ainda que as propostas de Lutero não tenham resultado, em curto prazo, na criação de um sistema educacional público e estatal, como conhecido hoje, convém reconhecer que essas estavam à frente de sua época, suscitando mudanças locais que, posteriormente, se espalharam por outras regiões e países. Assim, princípios presentes na gênese do que ele entendia e defendia como direito à educação para todos, vão permanecer e se perpetuar através dos séculos.

Desses princípios, destacam-se aqueles hoje reconhecidos internacionalmente e prescritos na Declaração Universal dos Direitos Humanos no que concerne ao direito à educação: que seja para todos; devendo ser gratuita e obrigatória, ao menos no nível elementar; com objetivos definidos (para o desenvolvimento individual e social/coletivo). 
Se, por um lado, é importante que há 500 anos Lutero tenha posto em marcha os referidos princípios, alimentando governantes, políticas e literaturas sobre o aperfeiçoamento do tema, por outro lado, devemos nos questionar em que medida Estado e sociedade avançaram na efetivação plena do direito à educação.

O século XXI iniciou-se combatendo a incapacidade de muitos países no avanço da promessa para a efetivação da garantia da educação primária gratuita e obrigatória para todas as crianças (TOMASEVSKI, 2001a). No Brasil, considerando a educação obrigatória, ainda há enormes desafios quanto à universalização do atendimento: na Educação Infantil, cerca de 500 mil crianças de 4 e 5 anos de idade encontram-se fora da escola; no Ensino Fundamental, ainda que alguns comemorem a universalização dessa etapa, 2,3\% das crianças entre 6 e 14 anos de idade, cerca de 430 mil pessoas, estão sem acesso à escola; no Ensino Médio concentra-se o maior número de adolescentes e jovens fora da escola: aproximadamente 1,5 milhão entre 15 e 17 anos de idade. Tal situação se agrava quando nos deparamos com a realidade de que cerca de 2,5 milhões de crianças e jovens de 4 a 17 anos de idade fora da escola pertencem às famílias mais pobres, estando entre eles a maior concentração de negros, indígenas e pessoas com deficiência. ${ }^{4}$ Ainda, o acesso e a matrícula na escola gratuita e compulsória não resolvem, necessariamente, graves problemas que devem ser enfrentados, como: a evasão escolar (sobretudo entre os jovens do Ensino Médio) e a falta de qualidade no atendimento, o que urge maiores investimentos e respeito às especificidades de cada etapa e modalidade da educação.

Dessa maneira, países como o Brasil têm alterado o seu ordenamento jurídico ao longo dos anos, incorporando e ampliando princípios reconhecidos internacionalmente como pertencentes ao direito à educação, contudo, os índices sociais e a extrema desigualdade de renda têm revelado que ao longo destes cinco séculos o "para todos" tornou-se promessa e, a igualdade, uma ilusão.

\section{REFERÊNCIAS}

ALTMANN, Walter. Lutero e libertação. São Paulo: Ática, 1994.

ASSIS, Ana Elisa Spaolonzi Queiroz. Direito à Educação e Diálogo entre Poderes. Tese de Doutorado. Faculdade de Educação. UNICAMP. 257 pg. 2012.

ASSIS, Ana Elisa Spaolonzi Queiroz. Creche não é direito público subjetivo: uma questão de política pública ou de interpretação jurídica?. In: Maria Lilia Imbiriba Sousa Colares; Sinara Almeida da Costa. (Org.). A educação infantil no centro do debate: do direito adquirido às práticas cotidianas desenvolvidas nas creches e pré-escolas. 1ed.Curitiba: CRV, 2017, v. 1, p. 55-73.

BARBOSA, Luciane Muniz R.. As concepções educacionais de Martinho Lutero. Educação e Pesquisa (USP), v. 33, p. 164-184, 2007.

4 Dados extraídos do Observatório da Educação. Disponível em: http://www.observatoriodopne.org.br/metas -pne. Acesso em: 30 mai. 2017. 
BARBOSA, Luciane Muniz R.. Estado e educação em Martinho Lutero: a origem do direito à educação. Cadernos de Pesquisa (Fundação Carlos Chagas. Impresso), v. 41, p. 866-885, 2011.

BARBOSA, Luciane Muniz R.. As origens do direito à educação: Martinho Lutero e a Reforma Protestante. Curitiba: CRV, 2017.

BRASIL. Constituição Política do Império do Brazil. Rio de Janeiro de 1824, RJ: Imperador, 1824. Disponível em: <http:/www.planalto.gov.br/ccivil_03/constituicao/constitui\%C3\%A7ao24.htm.> Acesso em: 20 jun. 2017.

. Constituição da República dos Estados Unidos do Brasil de 1891. Disponível

em: <http://www.planalto.gov.br/ccivil_03/Constituicao/Constitui\%C3\%A7ao91.htm.> Acesso em: 20 jun. 2017.

. Constituição da República dos Estados Unidos do Brasil de 1934. Disponível em: <http://www.planalto.gov.br/ccivil_03/Constituicao/Constitui\%C3\%A7ao34.htm.> Acesso em: 20 jun. 2017.

. Constituição dos Estados Unidos do Brasil de 1937. Disponível em: <http:// www.planalto.gov.br/ccivil_03/Constituicao/Constitui\%C3\%A7ao37.htm.> Acesso em: 20 jun. 2017.

. Constituição dos Estados Unidos do Brasil de 1946. Disponível em: <http:// www.planalto.gov.br/ccivil_03/constituicao/Constitui\%C3\%A7ao46.htm.> Acesso em: 20 jun. 2017.

. Constituição da República Federativa do Brasil de 1967. Disponível em: $<$ http://www.planalto.gov.br/ccivil_03/constituicao/Constitui\%C3\%A7ao67.htm.> Acesso em: 20 jun. 2017.

. Constituição da República Federativa do Brasil de 1988. Disponível em: $<$ http://www.planalto.gov.br/ccivil_03/constituicao/constitui\%C3\%A7ao.htm.> Acesso em: 20 jun. 2017.

. Declaração Universal dos direitos humanos 1948. Disponível em: $<$ http://portal.mj.gov.br/sedh/ct/legis_intern/ddh_bib_inter_universal.htm>. Acesso em: 20 jun. 2017. CAMBI, Franco. O Século XVI: o início da pedagogia moderna. In: História da Pedagogia. São Paulo: UNESP, 1999, p. 243-275 [Trad.: Álvaro Lorenci].

DEFREYN, Vanderlei. A Tradição escolar luterana: sobre Lutero, educação e a história das escolas luteranas até a Guerra dos Trinta Anos, 2004, 150s. Dissertação (Mestrado em Teologia) - Escola Superior de Teologia, São Leopoldo, RS.

EBY, Frederick. História da educação moderna: teoria, organização e práticas educacionais. Porto Alegre: Globo, 1976. 
HILSDORF, Maria Lúcia S. O Aparecimento da escola moderna: uma história ilustrada. Belo Horizonte: Autêntica, 2006.

LOPES, Eliane Marta T. Origens da educação pública: a instrução na revolução burguesa do século XVIII. São Paulo: Loyola, 1981.

LUTERO, Martinho. Aos conselhos de todas as cidades da Alemanha para que criem e mantenham escolas cristãs [1524]. In: Martinho Lutero: obras selecionadas. São Leopoldo: Comissão Interluterana de Literatura, 1995, v. 5, p. 299-325.

LUTERO, Martinho. Uma prédica para que se mandem os filhos à escola [1530]. In: Martinho Lutero: obras selecionadas. São Leopoldo: Comissão Interluterana de Literatura, 1995 , v. 5, p. 326-363.

LUTERO, Martinho. Educação e Reforma. São Leopoldo: Sinodal; Porto Alegre: Concórdia, 2000; Coleção Lutero para hoje.

LUZURIAGA, Lorenzo. A Educação pública religiosa. In: História da educação pública. São Paulo: Nacional, 1959, p. 5-11.

MANACORDA, Mário A. A Educação no Quinhentos e no Seiscentos. In: História da educação: da Antiguidade aos nossos dias. São Paulo: Cortez, 1989.

NUNES, Ruy A. da Costa. História da educação no renascimento. São Paulo: EPU, 1980.

OLIVEIRA, R. P. O Direito à Educação. In: OLIVEIRA, R. P.; ADRIÃO, T. (Orgs.). Gestão, Financiamento e Direito à Educação. São Paulo: Xamã, 2001.

RIETH, Ricardo. Apresentação. In: LUTERO, Martinho. Educação e Reforma. São Leopoldo: Sinodal; Porto Alegre: Concórdia, 2000; Coleção Lutero para hoje.

SACRISTÁN, G. A Educação Obrigatória: seu sentido educativo e social. Porto Alegre: Artmed, 2001.

SCHULTE, Andrea. Martin Luther and female education. In: https:/www.thefreelibrary. com/Martin+Luther+and+female+education.-a095148874, v. 29, 2002. Acesso em: 30 mai. 2017.

TOMASEVSKI, K. Free and compulsory education for all children: the gap between promise and performance. In: Right to Education Primers n. 2. Gothenburg: Novum Grafiska AB, 2001a.

TOMASEVSKI, K. Human rights obligations: making education available, accessible, acceptable and adaptable. In: Right to Education Primers n. 3. Gothenburg: Novum Grafiska AB, 2001b.

ZICHIA, A. C. O direito à educação no Período Imperial: um estudo de suas origens no Brasil. Dissertação (Mestrado em Educação). Faculdade de Educação da USP, São Paulo, 2008. 


\section{Dados das aUtoras}

\section{LUCIANE MUNIZ RIBEIRO BARBOSA}

Doutora em Educação pela Universidade de São Paulo. Professora da Faculdade de Educação da Universidade Estadual de Campinas, no Departamento de Políticas, Administração e Sistemas Educacionais. Campinas/SP - Brasil. lumuniz@unicamp.br

\section{ANA ELISA SPAOLONZI QUEIROZ ASSIS}

Doutora em Educação pela Universidade Estadual de Campinas. Coordenadora Associada do Curso de Pedagogia da Faculdade de Educação e Professora da Universidade Estadual de Campinas. Campinas/SP - Brasil. anaelisasqa@gmail.com

Submetido em: 23-6-2017

Aceito em:10-11-2017 